\title{
Preferência de Aphis craccivora por genótipos de feijão-caupi de porte prostrado, em Aquidauana, MS
}

\author{
Sérgio Roberto Rodrigues ${ }^{1}$, Osni de Oliveira Junior², Gessi Ceccon ${ }^{3}$, Agenor Martinho Correa ${ }^{4}$, \\ Alfredo Raúl Abot ${ }^{5}$
}

\section{RESUMO}

O feijão-caupi (Vigna unguiculata (L.) Walp.) é uma importante fonte de alimento. Na região centro-oeste do Brasil, poucos são os estudos desenvolvidos com essa cultura. Assim, foram desenvolvidos experimentos, em condições de campo, em Aquidauana, MS, visando encontrar genótipos menos preferidos pelo pulgão preto (Aphis craccivora) para infestação e colonização. Em abril e outubro de 2009, foram semeados 20 genótipos de porte prostrado e após a germinação verificou-se o número de fêmeas e colônias de pulgão presentes e aos 30 dias avaliou-se a porcentagem de plantas infestadas. No experimento conduzido em abril e maio, verificou-se que todos os genótipos de feijão-caupi foram colonizados por A. craccivora. Porém nos genótipos MNC99-537F-14-2 e BRS Paraguassu foram observadas as menores percentagens de colônias. Em maio encontrou-se as menores percentagens nos genótipos MNC99-537F-142, MNC01-631F-20-5 e BRS Paraguassu, com 6,3, 5,7 e 6,3\% de plantas infestadas, respectivamente. Dentre os genótipos estudados, conclui-se que MNC99-537F-14-2, MNC01-631F-20-5 e BRS Paraguassu, podem ser melhores estudados, visando à seleção de materiais resistentes ao pulgão preto.

Palavras-chave: Antixenose, resistência de plantas, Insecta, Vigna unguiculata.

\section{ABSTRACT}

\section{Preference of Aphis craccivora for prostrate cowpea genotypes, in Aquidauana, MS}

Cowpea (Vigna unguiculata (L.) Walp.) is an important food source. However, there is a lack of studies on this crop in Midwestern Brazil. Experiments were conducted in field conditions in Aquidauana, Mato Grosso do Sul, aiming to find genotypes less preferred by black aphid (Aphis craccivora (Koch.)). In April and October 2009, 20 prostrate genotypes were sown, and after germination the number of females and colonies were counted. At day 30, the percentage of infested plants was evaluated. In the experiment carried out in April and May, all genotypes were colonized by A. craccivora. However, the genotypes MNC99-537F-14-2 and BRS Paraguassu showed the smallest numbers of colonies. In May, the lowest percentages were found in the genotypes MNC99-537F-14-2, MNC01-631F20-5 and BRS Paraguassu, with 6.3, 5.7 and $6.3 \%$ of infested plants, respectively. Among the studied genotypes, MNC99-537F-14-2, MNC01-631F-20-5 and BRS Paraguassu should be further investigated for the selection of materials resistant to black aphids.

Key words: Antixenosis, cowpea, insecta, plant resistance, Vigna unguiculata.

\footnotetext{
Recebido para publicação em junho de 2010 e aprovado em novembro de 2010

${ }^{1}$ Engenheiro Agrônomo, Doutor. Unidade de Aquidauana, UEMS, Rodovia Aquidauana/CERA, km 12, 79200-000, Aquidauana, MS, Brasil. sergio@uems.br, autor para correspondência.

${ }^{2}$ Graduando do curso de Agronomia. Unidade de Aquidauana, UEMS, Rodovia Aquidauana/CERA, km 12, 79200-000, Aquidauana, MS, Brasil. osni_bio@yahoo.com.br

${ }^{3}$ Engenheiro Agrônomo, Doutor. Empresa Brasileira de Pesquisa Agropecuária (EMBRAPA) BR 163, km 253, Caixa Postal, 661, 79804-970, Dourados, MS, Brasil. gessi@cpao.embrapa.br

${ }^{4}$ Engenheiro Agrônomo, Doutor. Unidade de Aquidauana, UEMS, Rodovia Aquidauana/CERA, km 12, 79200-000, Aquidauana, MS, Brasil. agenor@uems.br

${ }_{5}^{5}$ Engenheiro Agrônomo, Doutor. Unidade de Aquidauana, UEMS, Rodovia Aquidauana/CERA, km 12, 79200-000, Aquidauana, MS, Brasil. arabot@uems.br
} 


\section{INTRODUÇÃO}

O feijão-caupi é cultivado em regiões de clima quente e seco sendo que Silva et al. (2002) encontraram teores de proteína nos grãos entre 20,29 a 29,29\%, demonstrando a importância da cultura como fonte de proteína. No entanto a cultura é suscetível ao ataque de diversas pragas que podem ocasionar perdas na produtividade.

As principais espécies de pragas que aparecem associadas ao feijão-caupi são das ordens, Lepidoptera: Elasmopalpus lignosellus (Zeller), Maruca testulalis (Geyer) e Etiella zinckenella (Treitschke), Coleoptera: Diabrotica speciosa (Germar), Cerotoma arcuata (Olivier), Chalcodermus bimaculatus Fiedler e Calosobruchus maculatus (Fabr.), Dipera: Liriomyza sativae Blanchard e Hemiptera: Aphis craccivora (Koch.), Empoasca kraemeri (Ross e Moore), Crinocerus sanctus (Fabr.), Piezodorus guildini Westwood, Acrosternum sp. e Bemisia tabaci (Genn.) (Quintela et al., 1991; Oliveira Junior et al., 2002; Costa et al., 2004; Freitas et al., 2006; Moraes, 2007).

As ninfas e adultos de A. craccivora sugam a seiva dos brotos terminais e pecíolos, podendo provocar deformação nas folhas, atraso no desenvolvimento além de disseminar viroses (Quintela et al., 1991).

Uma série de estudos com o feijão-caupi é encontrado na região Norte e Nordeste do Brasil, onde várias informações estão disponíveis sobre essa cultura incluindo a adaptação e seleção de cultivares (Lima et al., 2001; Oliveira et al., 2002; Silva et al. 2002; Freire Filho et al., 2005; Rocha et al., 2006, 2008; Moraes \& Bleicher, 2007; Santos et al., 2009; Fontes et al., 2010).

Na região Centro-Oeste são desconhecidos estudos sobre a associação de A. craccivora e cultivares de feijão-caupi, assim, o presente trabalho teve por objetivo verificar a preferência de $A$. craccivora por genótipos de feijão-caupi de porte prostrado, em condições de campo, em Aquidauana, MS.

\section{MATERIAL E MÉTODOS}

Os experimentos foram conduzidos na área experimental da Universidade Estadual de Mato Grosso do Sul, em Aquidauana, MS (20²8'S e $\left.55^{\circ} 48^{\prime} \mathrm{W}\right)$. As sementes de feijão-caupi são originárias do banco de germoplasma da EMBRAPA Meio-Norte, Teresina, PI.

Foram utilizados 20 genótipos de feijão-caupi de porte prostrado identificados com seus respectivos parentais ou local de origem como: MNC99-510F-16-1 (Paulista x TE90-180-88F), MNC99-510F-16-3 (Pauista x TE90-18088F), MNC99-537F-14-2 (TE96-282-22G x IT87D-611-3), MNC01-611F-11 (TE97-340-4E x TE93-222-11F), MNC01614F-15(TE97-404-1F-15 x TE93-242-10E-6-1-1), MNC01631F-11 (CNCx 409-11F-P2-195 x TE97-341-1E-1-1), MNC01-631F-15(CNCx 409-11F-P2-195 x TE97-341-1E-1-
1), MNC01-631F-20-5 (CNCX 409-11F-P2-195 x TE97-3411E-1-1), MNC01-649E-2 (TE97-309G-24 x MNC-01-608D2-5), Canapuzinho (proveniente de São Raimundo Nonato, PI), Canapuzinho-2 (São Raimundo Nonato, PI), Inhuma (Inhuma, PI), Pingo-de-ouro-1-2 (Iguatu, CE), Pingo-deouro-2 (Iguatu, CE), Paulistinha (Juazeiro, CE), Patativa (CNC1735 x (CNCx 926-5F x Paulista), BRS Paraguassu (BR10 - Piauí x CE-315), BRS Milênio (Tracuateua, PA), BR17 Gurguéia (BR 10-Piauí x CE-315) e BRS Marataoã (Seridó x TVx1836-013J).

Para instalação dos genótipos no campo, foram realizadas uma aração e duas gradagens, em seguida a adubação foi realizada aplicando-se $300 \mathrm{~kg} \mathrm{ha}^{-1}$ da fórmula química 4-20-20 de NPK. A semeadura foi realizada em abril de 2009 e em seguida a área foi irrigada para garantir a emergência uniforme. Depois de 25 dias da germinação, foi realizada adubação de nitrogênio em cobertura, aplicando-se $120 \mathrm{~kg} \mathrm{ha}^{-1}$ de uréia.

Os genótipos foram semeados novamente em outubro de 2009, sendo utilizadas as mesmas práticas culturais, entretanto como adubação de plantio foram aplicados $200 \mathrm{~kg} \mathrm{ha}^{-1} \mathrm{da}$ fórmula 4-20-20 (NPK), sem adubação de cobertura.

Os experimentos foram instalados utilizando-se o delineamento em blocos casualizados, com 20 genótipos e quatro repetições. Foram montadas parcelas com 4 linhas de 5 metros de comprimento e 0,8 metro entre linhas. Foram distribuídas 16 sementes por metro linear e após o desbaste realizado duas semanas após a semeadura, foram mantidas oito plantas por metro linear.

A partir da primeira semana após a germinação, foram iniciadas amostragens semanais dos pulgões nas parcelas, sendo amostradas aleatoriamente oito plantas/parcela, quantificando o número de fêmeas e de colônias de $A$. craccivora, na região do pecíolo e na folha trifoliolada mais nova, completamente aberta, conforme método adaptado de Moraes (2007).

Trinta dias após a emergência, foi quantificado o número de plantas com colônias, calculando-se a porcentagem de infestação por genótipo em cada plantio. Nos genótipos nas duas épocas de semeadura, foram quantificados os tricomas (acicular e unciforme) em 0,5 $\mathrm{cm}^{2}$ nas faces adaxial e abaxial, utilizando estereomicroscópio (aumento de 40x) segundo métodos adaptados de Oriani et al. (2005). No pecíolo os tricomas foram quantificados em $0,5 \mathrm{~cm}$ de comprimento.

Os dados sobre número de fêmeas, colônias e tricomas foram transformados em $\sqrt{x+1}$, e o percentual de infestação, transformados em arcseno $\sqrt{x+1} / 100$, por terem apresentado heterocedasticidade de variâncias. Os dados foram submetidos à análise de variância e as médias comparadas pelo teste de Scott-Knott $(\mathrm{P}<0,05)$. As análises foram realizadas pelo programa computacional 
ASSISTAT (Silva \& Azevedo, 2002). Realizou-se também análise de correlação (Pearson) entre as quantidades de tricomas com as quantidades de pulgões e tricomas com a porcentagem de infestação $(\mathrm{P}<0,05)$.

\section{RESULTADOS E DISCUSSÃO}

Nas avaliações realizadas em maio, verificou-se que todos os genótipos de feijão-caupi foram colonizados por fêmeas de A. craccivora, não havendo, diferenças significativas entre os materiais testados (Figura 1 ).

Nas amostragens de outubro e novembro, também não foram observadas diferenças significativas entre as quantidades de pulgões nos genótipos, embora o genótipo Patativa apresentasse a quantidade mais elevada de fêmeas (Figura 1).

Nas avaliações de maio foram observadas diferenças significativas entre os materiais avaliados quanto às colônias de A. craccivora (Figura 2). Nos genótipos MNC99537F-14-2 e BRS Paraguassu, foram observadas as menores quantidades de colônias (Figura 2).

Os genótipos MNC01-614F-15, MNC01-631F-20-5, MNC01-649E-2 também se destacaram pelas menores quantidades de colônias de A. craccivora, amostradas em maio (Figura 2). Verifica-se que as fêmeas localizaram esses materiais no campo, porém, poucas plantas foram colonizadas. Nas avaliações realizadas em outubro e novembro, não foram observadas diferenças significativas entre os genótipos (Figura 2).

Moraes (2007) em seus estudos conduzidos em campo, não encontrou diferenças entre as quantidades de colônias de A. craccivora por genótipos de feijão-caupi, concluindo que todos foram igualmente preferidos.
Quanto as percentagens de infestações, encontrouse em maio nos genótipos MNC99-537F-14-2, MNC01631F-20-5 e BRS Paraguassu, as mais baixas percentagens de infestações por $A$. craccivora, embora não se tenha detectado diferenças significativas entre os genótipos (Figura 3).

No presente experimento BRS Marataoã, apresentou 14,90\% de infestação de A. craccivora. Moraes (2007) verificou em testes conduzidos em casa de vegetação, que BRS Marataoã atraiu várias fêmeas e originou grandes quantidades de ninfas por fêmea de A. craccivora, demonstrando ser favorável ao desenvolvimento dessa praga.

Alguns genótipos apresentaram maiores percentagens de infestações por A. craccivora e segundo Moraes \& Bleicher (2007) em seus experimentos as cultivares Epace11, Pitiúba e Pingo de Ouro foram as mais preferidas por A. craccivora em teste com chance de escolha e apresentaram maior número de ninfas por planta.

No presente trabalho, o genótipo BR17 Gurguéia apresentou $25,75 \%$ de infestação por A. craccivora nas avaliações de maio, e 6,21\% de infestação em novembro (Figura 3). Moraes (2007) em seus experimentos verificou que BRS17 Gurguéia, permitiu o bom desenvolvimento de $A$. craccivora em testes conduzidos em casa de vegetação.

Moraes \& Bleicher (2007) verificaram que o genótipo BR17 Gurguéia, teve alta quantidade de fêmeas adultas e alta quantidade de ninfas por plantas, demonstrando ser adequada ao desenvolvimento e reprodução de $A$. craccivora. As porcentagens de infestações encontradas em BR17 Gurguéia, e as informações encontradas por outros pesquisadores demonstram que esse genótipo está

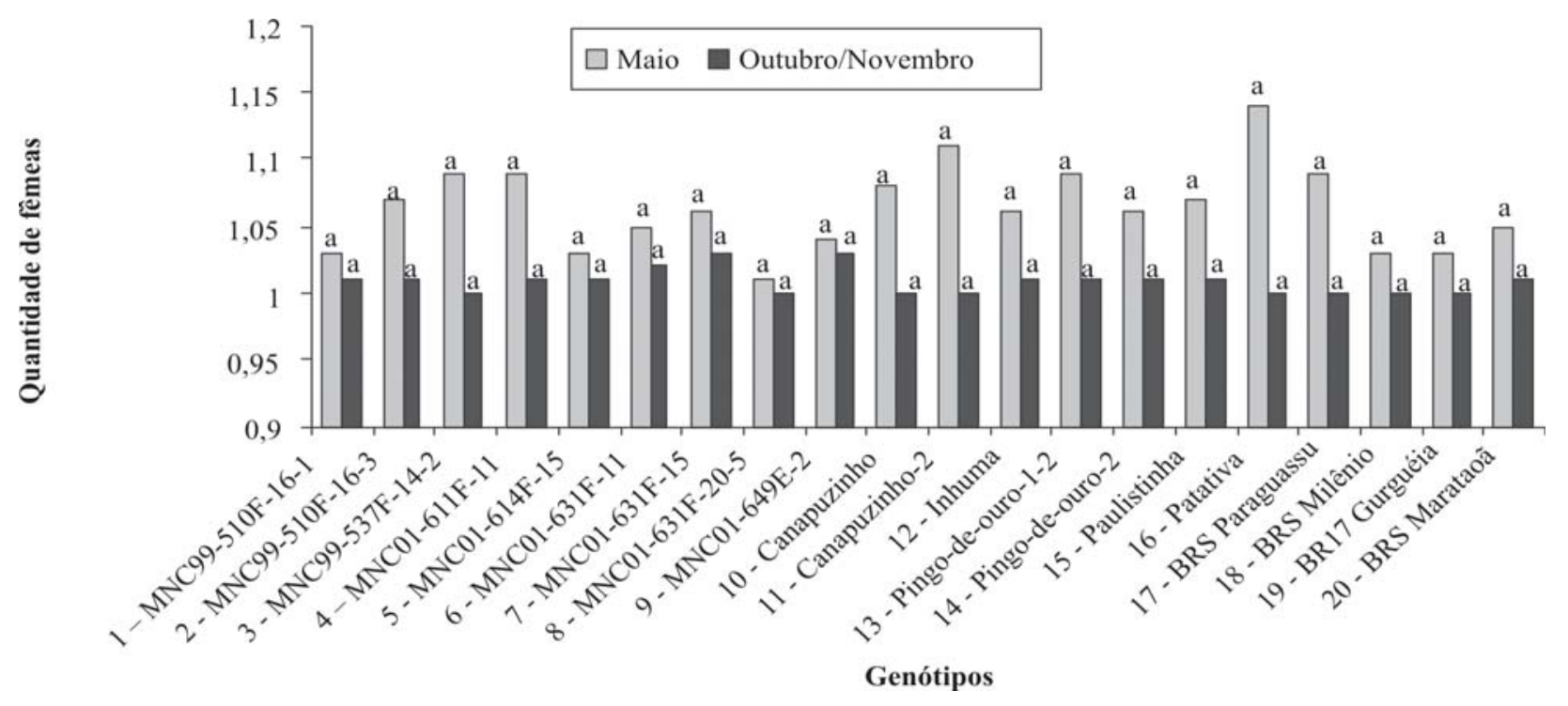

Figura 1. Quantidade média de fêmeas de Aphis craccivora em genótipos de feijão- caupi (Vigna unguiculata), em Aquidauana, MS, em maio, outubro e novembro de 2009. Em cada época de avaliação, médias seguidas pelas mesmas letras não diferem entre si pelo teste de Scott-Knott $(\mathrm{p}>0,05)$. 
sendo favorável ao desenvolvimento dessa praga a região de Aquidauana, MS.

Em Aquidauana, MS, o genótipo Patativa apresentou 25,98\% de infestação na avaliação de maio, sendo essa a média mais elevada de infestação amostrada (Figura 3). Entretanto, segundo Moraes \& Bleicher (2007) o genótipo Patativa é menos preferido, por A. craccivora pois, nos seus experimentos, foram encontradas menores quantidades de adultos e de ninfas por plantas. É possível que as condições ambientais na região de Aquidauana não permitam que o genótipo Patativa expresse sua capacidade de não preferência, como verificado por Moraes e Bleicher (2007), em experimentos conduzidos em Fortaleza, CE.

Oghiakhe (1995) quantificou no cultivar TVnu 72 de feijão-caupi, a média de 17,9 tricomas glandulares e 9,1 não glandulares na superfície adaxial por $\mathrm{mm}^{2}$, e 24,3 e 15,1 tricomas glandulares e não glandulares por $\mathrm{mm}^{2}$ res-

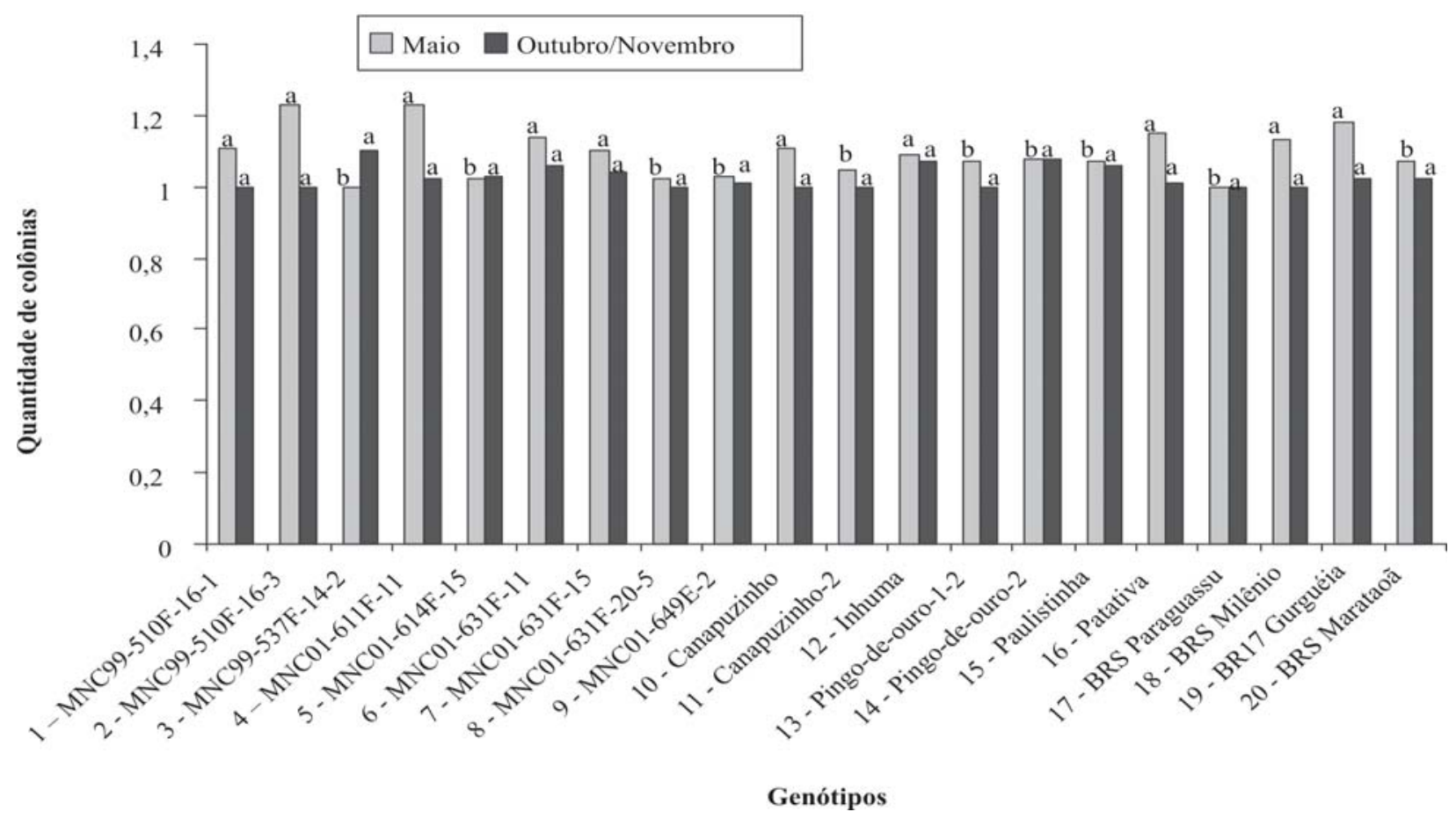

Figura 2. Quantidade média de colônias de Aphis craccivora em genótipos de feijão-caupi (Vigna unguiculata), em Aquidauana, MS, em maio, outubro e novembro de 2009. Em cada época de avaliação, médias seguidas pelas mesmas letras não diferem entre si pelo teste de Scott-Knott ( $\mathrm{p}>0,05)$.

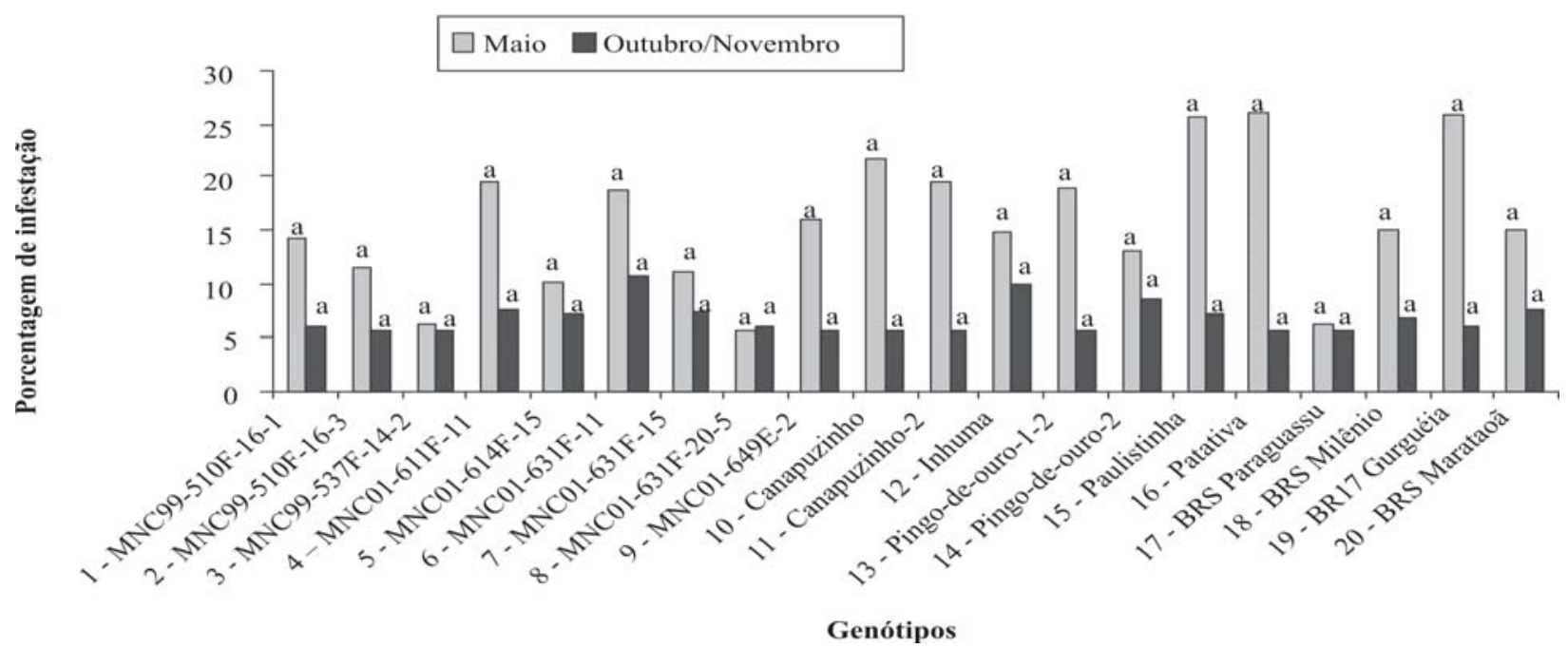

Figura 3. Porcentagem de infestação de Aphis craccivora em genótipos de feijão-caupi (Vigna unguiculata), em Aquidauana, MS, em maio e novembro de 2009. Em cada época de avaliação, médias seguidas pelas mesmas letras não diferem entre si pelo teste de ScottKnott ( $>$ 0,05).

Rev. Ceres, Viçosa, v. 57, n.6, p. 751-756, nov/dez, 2010 


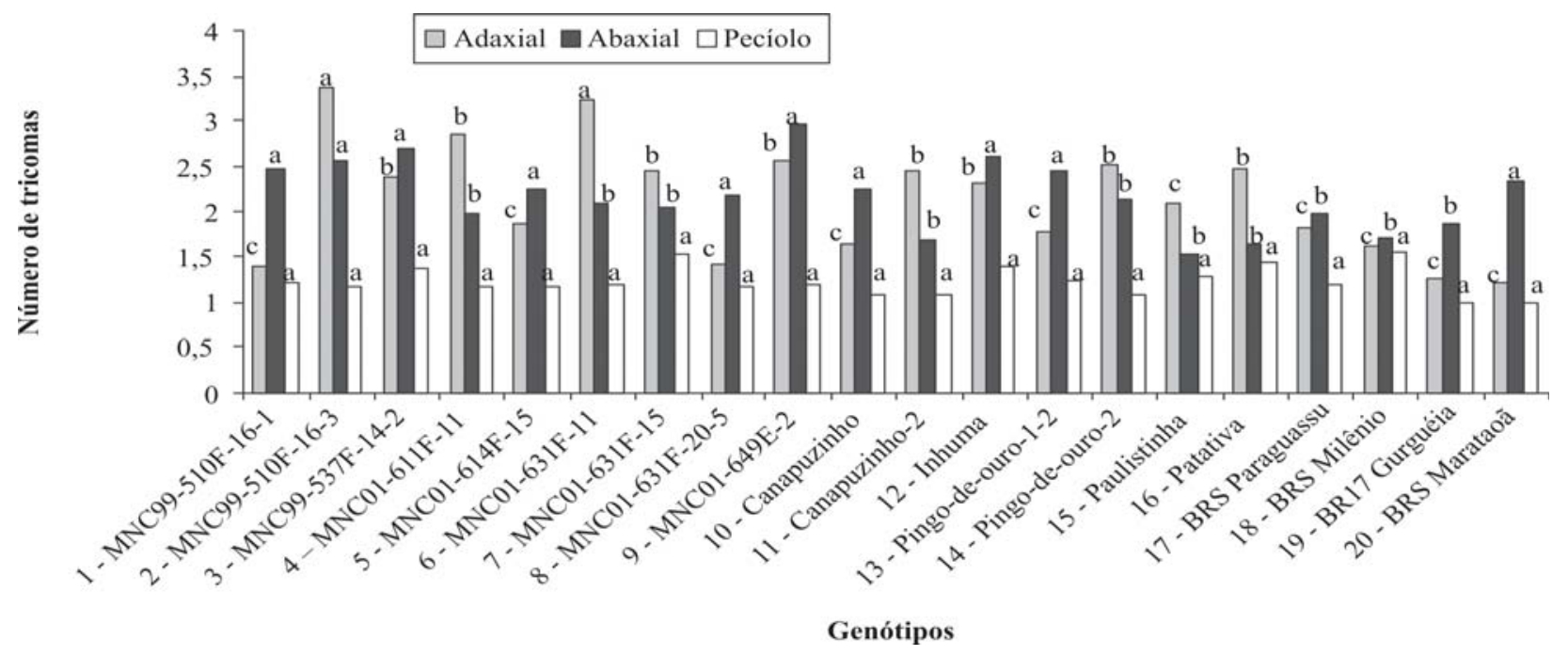

Figura 4. Número médio de tricomas na face abaxial, adaxial e pecíodo em genótipos de feijão-caupi (Vigna unguiculata), cultivados em Aquidauana, MS. Em cada época de avaliação, médias seguidas pelas mesmas letras não diferem entre si pelo teste de Scott-Knott $(\mathrm{p}>0,05)$.

pectivamente, na superfície abaxial, classificando-o como cultivar com alta quantidade de tricomas. Assim, as quantidades de tricomas não glandulares encontradas nos genótipos em análise na região de Aquidauana, podem ser consideradas como pequenas quantidades nas folhas e pecíolos (Figura 4).

A pilosidade encontrada aparentemente pouco interfere na preferência dos adultos de A. craccivora, pois os genótipos MNC99-537F-14-2, MNC01-631F-20-5 e BRS Paraguassu, que apresentaram menores porcentagens de infestações em maio, apresentaram também pequenas quantidades de tricomas. Assim, é provável que outros fatores estejam interferindo na colonização e reprodução de A. craccivora, nos genótipos de feijão-caupi. Provavelmente, componentes químicos presentes nas plantas estejam interferindo na preferência pelo pulgão.

Ao se correlacionar as quantidades de tricomas da face adaxial de folhas com as quantidades de pulgões, obteve-se baixo valor de correlação ( $\mathrm{r}=0,18, \mathrm{P}=0,0001)$, o mesmo foi observado na correlação de tricomas da face abaxial de folhas com pulgões ( $\mathrm{r}=0,10, \mathrm{P}=0,00002)$ e na correlação entre tricomas do pecíolo e pulgões $(r=0,03, P=0,0008)$. As porcentagens de infestações apresentaram baixo coeficiente de correlação com os tricomas presentes nos genótipos avaliados $(\mathrm{r}=-0,08$, $\mathrm{P}=0,002)$. Assim, não se verifica relação entre tricomas com quantidade de pulgões e porcentagens de infestações.

Dentre os genótipos estudados, verifica-se que MNC99-537F-14-2, MNC01-631F-20-5 e BRS Paraguassu, podem ser mais bem estudados, visando-se a seleção de cultivares resistentes à A. craccivora, face às quantidades mais baixas de fêmeas, colônias e infestações encontradas.

\section{CONCLUSÕES}

Os genótipos MNC99-537F-14-2, MNC01-631F-20-5 e BRS Paraguassu foram menos preferidos por $A$. craccivora.

\section{REFERÊNCIAS}

Costa NP, Santos TM \& Boiça Júnior AL (2004) Preferência para oviposição de Bemisia tabaci biótipo-B em genótipos de caupi. Acta Scientiarum, 26:227-230.

Fontes JRA, Gonçalves JRP \& Morais RR (2010) Tolerância do feijão-caupi ao herbicida oxadiazon. Disponível em: <http:// www.revistas.ufg.br/index.php/pat/issue/view/750>. Acessado em 20 de abril de 2010.

Freire Filho FR, Ribeiro VQ, Alcântara JP, Belarmino Filho J \& Rocha MM (2005) BRS Marataoã: Novo cultivar de feijãocaupi com grão tipo sempre-verde. Revista Ceres, 52:771777.

Freitas JRB, Pádua LEM, Silva PRR \& Moura JZ (2006) Avaliação do nível de dano do percevejo-vermelho-do-caupi Crinocerus sanctus (Fabricius 1775), (Hemiptera: Coreidae) em feijão-caupi (Vigna unguiculata Walp.). Disponível em: <http:// www.cpamn.embrapa.br/anaisconac2006/resumos/FS09.pdf $>$. Acessado em 08 de março de 2010.

Lima MPL, Oliveira JV, Barros R, Torres JB \& Gonçalves MEC (2001) Estabilidade da resistência de genótipos de caupi a Callosobruchus maculatus (Fabr.) em gerações sucessivas. Scientia Agricola, 59:275-280.

Moraes JGL (2007) Comportamento de genótipos de feijão-decorda sob infestação de pragas. Dissertação de Mestrado. Universidade Federal do Ceará, Fortaleza, 52p.

Moraes JGL \& Bleicher E (2007) Preferência do pulgão-preto, Aphis craccivora Koch, a diferentes genótipos de feijão-decorda, Vigna unguiculata (L.) Walp. Ciência Rural, 37:15541557.

Oghiakhe S (1995) Effect of pubescence in cowpea resistance to the legume pod borer Maruca testulalis (Lepidoptera: Pyralidae). Crop Protection, 14:379-387. 
Oliveira AP, Tavares Sobrinho J, Nascimento JT, Alves AU, Albuquerque IC \& Bruno GB (2002) Avaliação de linhagens e cultivares de feijão-caupi, em Areia, PB. Horticultura Brasileira, 20:180-182.

Oliveira Junior JO, Medeiros RD, Silva PRVP, Smiderle OJ \& Mourão Junior M (2002) Técnicas de manejo para o cultivo do caupi em Roraima. Boa Vista, Embrapa Roraima 18p. (Circular Técnica 3).

Oriani MAG, Vendramim JD \& Brunherotto R (2005) Influência dos tricomas na preferência para oviposição de Bemisia tabaci (Genn.) biótipo B (Hemiptera: Aleyrodidae) em genótipos de feijoeiro. Neotropical Entomology, 34:97-103.

Quintela ED, Neves BP, Quinderé MAW \& Roberts DW (1991) Principais pragas do caupi no Brasil. Goiânia, Embrapa-CNPAF 38p. (Documentos 35).

Rocha MM, Freire Filho FR, Ramos SRR, Ribeiro VQ, Andrade FN \& Gomes RLF (2006) Avaliação agronômica de genótipos de feijão-caupi para produção de grãos verdes. Teresina, Embrapa Meio-Norte 16 p. (Boletim de Pesquisa e Desenvolvimento $67)$
Rocha MM, Oliveira JTS, Freire Filho FR, Câmara JAS, Ribeiro VQ \& Oliveira, JA (2008) Purificação genética e seleção de genótipos de feijão-caupi para a região semi-árida Piauiense. Teresina, Embrapa Meio-Norte 28p. (Boletim de Pesquisa e Desenvolvimento 84).

Santos JF, Grangeiro JIT, Brito CH \& Santos MCCA (2009) Produção e componentes produtivos de variedades de feião caupi na microrregião Cariri Paraibano. Engenharia Ambiental, 6:214222.

Silva SMS, Maia JM, Araújo ZB \& Freire Filho FR (2002) Composição química de 45 genótipos de feijão-caupi (Vigna unguiculata (L.) Walp). Teresina, Embrapa Meio-Norte 2p. (Comunicado Técnico 149).

Silva FAS \& Azevedo CAV (2002) Versão do programa computacional Assistat para o sistema operacional Windows. Revista Brasileira de Produtos Agroindustriais, 4:71-78. 